\title{
Quality indicators for a geriatric emergency care (GeriQ-ED) - an evidence-based delphi consensus approach to improve the care of geriatric patients in the emergency department
}

Susanne Schuster ${ }^{1,2,3^{*}+}$ D , Katrin Singler ${ }^{4,5+}$, Stephen Lim $^{6}$, Mareen Machner ${ }^{7,8}$, Klaus Döbler ${ }^{9}$ and Harald Dormann ${ }^{1,2}$

\begin{abstract}
Introduction: In emergency care, geriatric requirements and risks are often not taken sufficiently into account. In addition, there are neither evidence-based recommendations nor scientifically developed quality indicators (QI) for geriatric emergency care in German emergency departments. As part of the GeriQ-ED@ research project, quality indicators for geriatric emergency medicine in Germany have been developed using the QUALIFY-instruments.

Methods: Using a triangulation methodology, a) clinical experience-based quality aspects were identified and verified, b) research-based quality statements were formulated and assessed for relevance, and c) preliminary quality indicators were operationalized and evaluated in order to recommend a feasible set of final quality indicators.

Results: Initially, 41 quality statements were identified and assessed as relevant. Sixty-seven QI (33 process, 29 structure and 5 outcome indicators) were extrapolated and operationalised. In order to facilitate implementation into daily practice, the following five quality statements were defined as the GeriQ-ED@ TOP 5: screening for delirium, taking a full medications history including an assessment of the indications, education of geriatric knowledge and skills to emergency staff, screening for patients with geriatric needs, and identification of patients with risk of falls/ recurrent falls.

Discussion: Qls are regarded as gold standard to measure, benchmark and improve emergency care. GeriQ-ED@ QI focused on clinical experience- and research-based recommendations and describe for the first time a standard for geriatric emergency care in Germany. GeriQ-ED@ TOP 5 should be implemented as a minimum standard in geriatric emergency care.
\end{abstract}

\footnotetext{
* Correspondence: susanne.schuster@evhn.de

†'Susanne Schuster and Katrin Singler contributed equally to this work.

${ }^{1}$ Faculty of Medicine, Friedrich-Alexander University Erlangen-Nürnberg,

Erlangen, Germany

${ }^{2}$ Emergency Department, Klinikum Fürth, Fürth, Germany

Full list of author information is available at the end of the article
}

C C The Author(s). 2020 Open Access This article is licensed under a Creative Commons Attribution 4.0 International License, which permits use, sharing, adaptation, distribution and reproduction in any medium or format, as long as you give appropriate credit to the original author(s) and the source, provide a link to the Creative Commons licence, and indicate if changes were made. The images or other third party material in this article are included in the article's Creative Commons licence, unless indicated otherwise in a credit line to the material. If material is not included in the article's Creative Commons licence and your intended use is not permitted by statutory regulation or exceeds the permitted use, you will need to obtain permission directly from the copyright holder. To view a copy of this licence, visit http://creativecommons.org/licenses/by/4.0/ The Creative Commons Public Domain Dedication waiver (http://creativecommons.org/publicdomain/zero/1.0/) applies to the data made available in this article, unless otherwise stated in a credit line to the data. 


\section{Introduction}

Every third patient admitted to prehospital emergency medicine and clinical emergency medicine is older than 65 years old [1-3]. Demographic changes have led to unique challenges faced by emergency care.

Functional decline, cognitive impairments, such as delirium or dementia, multiple comorbidities, frailty, falls and polypharmacy often result in negative health outcomes [4-8] It is known that in geriatric emergency patients, the risk of adverse outcomes such as hospital (re) admission, institutionalisation and mortality are increased compared to younger patients $[9,10]$.

The American College of Emergency Physicians (ACEP), the American Geriatrics Society (AGS), the Emergency Nurses Association (ENA) and the Society for Academic Emergency Medicine (SAEM) have developed guidelines for the care of older people in the emergency department (ED) [11]. However, in Australia and Europe, there are currently no consensus on which aspects of care to be included [7, 8, 12, 13]. To bring together both disciplines, geriatrics and emergency medicine, a European curriculum in geriatric emergency medicine was developed and approved by the European Union of Medical Specialists (UEMS) [14]. Additionally, a position paper by the German Society of Emergency Medicine (DGINA), the German Society of Geriatrics (DGG), the German Society of Gerontology and Geriatrics (DGGG), the Austrian Society of Geriatrics and Gerontology (ÖGGG) and the Swiss Society for Geriatrics (SFGG) have identified the need for further research and objective quality indicators (QIs) for geriatric emergency care [15]. A recent review highlighted that "a balanced, methodologically robust set of QIs for care of older persons in the ED" is needed [16]. Well-defined QIs will enable the assessment, benchmarking, and improvement of quality of care for geriatric emergency care patients [17].
During the development of the QIs, the following quality criteria were considered: scientific character, relevance and feasibility [18].

The aim of this paper is to describe the development process of QIs for the management of geriatric emergency patients and to provide a set of structure, process and outcome QIs (GeriQ-EDC).

\section{Methods}

Triangulation methodology was applied for the development of the quality indicators, based on exploration of current evidence through a systematic literature search, and expert opinion from an interdisciplinary and interprofessional expert panel.

Action steps (Fig. 1):

- clinical experience-based quality aspects (QA) were identified and verified,

- evidence-based quality statements (QS) were formulated and assessed for relevance,

- preliminary quality indicators (QI) were operationalized and evaluated in order to recommend a feasible set of final quality indicators.

An exploratory literature review was conducted between $09 / 2014-10 / 2014$ and an expert panel $(n=11)$ was established to contribute with its expertise on geriatric emergency care through a Delphi process [19]. The expert panel consisted of three emergency physicians and specially trained nurses, a geriatrician, a pharmacologist, a health economist and two participants who represented the views of older emergency patients.

At the first expert meeting $(11 / 2014)$ a qualitative group discussion among the expert panel was conducted to identify relevant quality aspects of care for geriatric emergency patients. These quality aspects were evaluated using qualitative content analysis according to

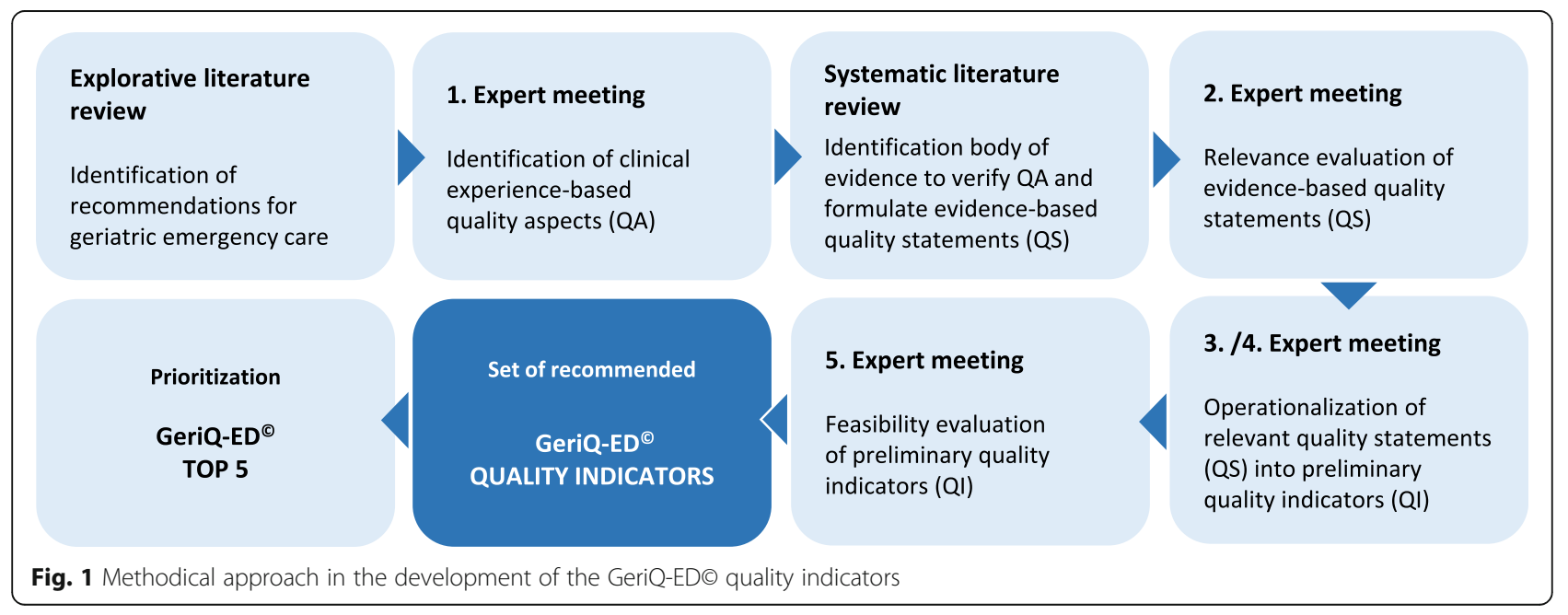


Mayring supported by MAXQDA [20]. A second systematic literature review (12/2014-03/2015) [search terms: 'geriatric OR elderly OR senior' AND 'emergency department'; databases: PubMed and CINAHL; inclusion criteria: published scientific papers, reviews, systematic reviews and meta-analyses between 2010 and 2015] was conducted to explore evidence for the potentially relevant quality aspects identified by the expert panel. Another aim of this systematic literature review was to verify the clinical experience-based quality aspects and to formulate evidence-based quality statements. During the second expert meeting (03/2015) an anonymized assessment of the relevance of all quality statements was conducted by the panel using a fourstaged Likert-scale. The assessment took into consideration the importance, benefit and risk of each quality statement, based on the QUALIFY- instrument [19]. During the operationalisation process (third and fourth expert meeting - 05/2015 and 06/2015) preliminary quality indicators (structural, process or outcome indicators) including respective reference ranges were defined for every quality statement that was classified as relevant. To facilitate implementation of the preliminary quality indicators (QIs) into daily practice, QIs were assessed for their feasibility. To find a consensus during the fifth meeting (12/2015), experts used the anonymized two-step approach by RAND UCLA [21]. Finally, the panel was asked to define the QIs of five quality statements they regarded to be most important. These were prioritized as the "top five".

\section{Results}

The explorative literature review identified defined topics of geriatric emergency care [7, 8] QIs for selected areas in the field [13] and guidelines for geriatric emergency departments (ED) [11]. The potentially relevant quality aspects that were discussed during the first expert meeting were summarized into twelve different categories: education, staff, equipment, communication/ information transfer, nursing care, medical treatment, geriatric screening, and risk factors such as falls, pain, cognitive impairment, medication and care needs (incontinence and the development of pressure sores).

The systematic literature review of potentially relevant quality aspects identified nine reviews, seven systematic reviews and two meta-analyses. Based on these results 41 quality statements were formulated. At the second meeting of the expert panel all 41 quality statements were assessed as being relevant. The following quality statements were rated as most relevant $(\overline{\mathrm{X}}=$ mean value $)$ :

- screening for delirium $(\overline{\mathrm{X}} 3,93)$

- professional training requirements for emergency care staff $(\overline{\mathrm{X}} 3,90)$

- barrier-free access to toilets with the possibility of supported transfer ( $\overline{\mathrm{X}} 3,90)$

- repetitive pain assessment including appropriate use of analgesics $(\overline{\mathrm{X}} 3,90)$

During their third and fourth meeting the expert panel operationalized the 41 quality statements into 69 QIs. Apart from the statement 'to implement a separate waiting area for geriatric patients', the expert panel considered all other QIs as feasible at the fifth expert meeting.

Finally, a set of 67 clinical experience- and evidence-based GeriQ-ED॰ QIs (33 process QI, 29 structural QI and 5 outcome QI), which were relevant and feasible, were developed and operationalized (English translation of GeriQ-EDC available under additional online material). In 2017 GeriQ-ED॰ QIs have been published and are available for free on the website of the German Society of Emergency Medicine (DGINA) [22].

Table 1 shows an example of a GeriQ-EDC quality indicator regarding cognitive impairment/ delirium:

Table 1 Example for GeriQ-ED@: cognitive impairment/delirium

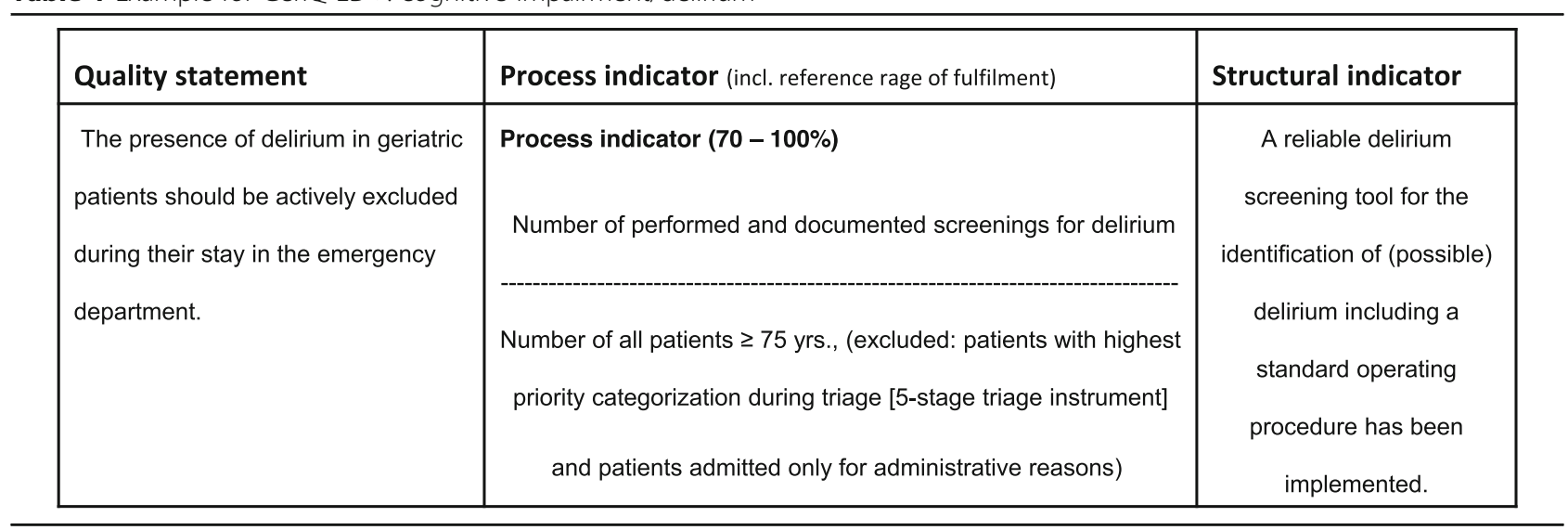


In order to facilitate implementation into daily practice, the following five quality statements (associated with twelve quality indicators [22] https://www.dgina.de/ news/geriq-c-quality-indicators-for-geriatric-emergencycare-entwicklung-von-qualitatsindikatoren-fur-die-versorgung-von-geriatrischen-notfallpatienten_63) were defined as the GeriQ-ED॰ TOP 5:

1. screening for delirium

2. taking a full medication history including an assessment of the indications

3. education of geriatric knowledge and skills to emergency staff

4. screening for patients with geriatric needs

5. identification of patients with risk of falls/ recurrent falls

\section{TOP 1: screening for delirium}

Consequences of an undetected delirium include progressive deterioration of functional and cognitive impairment, and an increased risk of mortality [23, 24]. Studies show a strong association between the duration of delirium and mortality $[25,26]$. Thus early detection of delirium in the emergency care setting is essential. Currently only a few screening-tools are validated and feasible in daily practice in the ED, such as the Confusion Assessment Method (CAM), the modified CAM-ED (mCAMED) $[27,28]$ and the 4-AT [29].

According to GeriQ-ED९, a standardized screening of delirium is recommended using a validated instrument that is feasible in the department settings. Although the exact timing of the screening in the emergency care process was not defined by the expert panel, delirium should be screened at the earliest time that is feasible in the ED management of the patient. In patients directly discharged from the ED, screening should be conducted prior to discharge. In addition, GeriQ-ED® recommends the implementation of a standardized management for patients at risk of delirium or patients with delirium including the documentation of risk factors as well as initial management of risk reduction as feasible in the ED [22] https:// www.dgina.de/news/geriq-c-quality-indicators-for-geriatric-emergency-care-entwicklung-von-qualitatsindikatorenfur-die-versorgung-von-geriatrischen-notfallpatienten_63.

\section{TOP 2: medication history including indications}

Polypharmacy is common among older adults and is associated with an increased risk of adverse outcomes such as adverse drug reactions or medication errors. Adverse drug events (ADR) are a major cause of ED visits among older people $[8,30-32]$. Nevertheless, most ADR are not detected. Studies have shown that up to $60 \%$ of all ADR are potentially avoidable [33]. Special attention should be given to the intake of anticoagulants, benzodiazepines, non-steroidal anti-inflammatory drugs, diuretics and antidepressants. These classes of drugs have in many cases been associated with complaints from older people who have been admitted to ED [32, 34-37].

Good clinical practice for the detection and prevention of ADRs in vulnerable patients include a detailed documentation and regular review of prescribed as well as over-the-counter medication by using a standardized medication reconciliation [38].

GeriQ-ED $\odot$ recommends the implementation of a comprehensive medication management, including a detailed documentation of the current medication as well as a possible indication for each medication. Medication history and possible missing information on current medication should also be documented in the ED [22] https://www.dgina.de/news/geriq-c-quality-indicators-for-geriatric-emergency-care-entwicklung-von-qualitatsindikatoren-fur-die-versorgung-vongeriatrischen-notfallpatienten_63.

\section{TOP 3: staff education on geriatric knowledge and skills}

Staff education level affects clinical outcomes in the emergency management [39]. In 2015 the Geriatric Section of the European Society for Emergency Medicine (EUSEM) together with the European Geriatric Medicine Society (EUGMS) established a joint task force to developed a curriculum for the care of older emergency patients (European Taskforce on Geriatric Emergency Medicine, ETFGEM). The aim was to outline relevant competencies in the care of older people, especially those with frailty. The curriculum incorporates knowledge on the physiology of ageing, common and atypical complaints, and the identification of geriatric syndromes or psychiatric needs of geriatric patients [14].

GeriQ-ED॰ confirms the need for an improvement in relevant competencies (knowledge and skills) of staff members who are involved in the care of older emergency patients and recommends for least $60 \%$ of the ED staff (physicians and nurses) the participation in at least one special geriatric training every year [22] https:// www.dgina.de/news/geriq-c-quality-indicators-for-geriatric-emergency-care-entwicklung-von-qualitatsindikatoren-fur-die-versorgung-von-geriatrischen-notfallpatienten_63.

\section{TOP 4: screening for patients with geriatric needs}

A recent meta-analysis showed that risk stratification of geriatric emergency patients is strongly limited by the lack of feasible and validated instruments. Existing instruments designed for risk stratification of older ED patients do not distinguish precisely between high- or lowrisk groups [40]. However, as long as no better screening instruments are developed, it is recommended to use established and validated instruments [41]. 
GeriQ-ED® proposes the use one of the currently recommended evidence-based screening-tools in the ED to identify geriatric needs for action. Comprehensive geriatric assessment and extrapolated management have been shown to improve the outcome of older multimorbid people [42]. Further, GeriQ-EDC recommends a standardized implementation of management including screening of geriatric needs, and accurate documentation and information transfer. The timing to screen for geriatric needs was not defined [22] https://www.dgina.de/ news/geriq-c-quality-indicators-for-geriatric-emergencycare-entwicklung-von-qualitatsindikatoren-fur-die-versorgung-von-geriatrischen-notfallpatienten_63.

\section{TOP 5: identification of patients with risk of falls/ recurrent falls}

Appropriate evaluation of a fallen patient not only implies a thorough assessment for traumatic injuries, but also an assessment of potential causes and a stratification of future risk of falling $[43,44]$. A proper assessment often requires a multidisciplinary team-approach. Currently no specific tools are recommended for the identification of potential risk factors [11]. The German Expert's Standard for Fall and Fracture Prevention recommends an evaluation of person-, medication- and environmental-related risk factors such as fall history, the use of walking aids, depression, cognitive impairment and the long-term use of more than six different drugs [45].

GeriQ-ED॰ recommends the assessment and documentation of risk factors for falling during patient's stay in the ED. The corresponding quality indicator recommends the documentation of $>80 \%$ of all patient cases in ED patients older than 70 years. Furthermore, it is recommended that every year more than $80 \%$ of the emergency nurses are trained on risk factors for falls [22] https://www.dgina.de/news/geriqc-quality-indicators-for-geriatric-emergency-careentwicklung-von-qualitatsindikatoren-fur-die-versorgung-von-geriatrischen-notfallpatienten_63.

\section{Discussion}

High-quality geriatric emergency care is needed to ensure patient safety for this high-risk group. QIs are regarded as gold standard to measure, benchmark and improve emergency care. GeriQ-ED $\odot$ focused on clinical experience and evidence-based recommendations and addressed the knowledge gap in this area. The proposed set of 67 GeriQ-ED(- ${ }^{-}$QIs serves as a guidance for geriatric emergency care to ensure quality of care $[7,8,46]$ and meets the recommendations made by the German position paper. For the first time QIs were developed that cover comprehensive geriatric emergency care and not only selected syndromes or fields of interest among geriatric emergency patients [13, 25, 47]. The operationalisation of quality statements into QIs enables an integration of them in existing documentation systems. The classification of quality aspects into twelve categories facilitates a thematic selection for special nursing or medical care issues.

In order to facilitate the implementation of QIs for older patient's emergency care, the expert panel defined the top 5 out of the assigned 67 QIs.

\section{Implications for emergency care}

GeriQ-ED॰ provide a set of 67 QIs including 33 process, 29 structure and 5 outcome indicators. They are intended as a framework for the provision of high quality geriatric emergency medicine adapted to the German emergency care. The QIs are intended to give the opportunity to assess own geriatric emergency care and to benchmark with other EDs. The QIs also give the opportunity to set individual goals for quality improvement in geriatric emergency care and to document the improvement accordingly.

To implement the 67 GeriQ-ED॰ QIs in the emergency care setting, further structural adaptations will be necessary. Individualised care of geriatric patients in order to improve the quality of care will require an adapted calculation of staff numbers in the EDs. Hospital management, leaders of EDs as well as ED nurse managers need to recognise that geriatric emergency patients ought to be considered as a highly vulnerable patient group with special needs that have to be addressed differently from usual care.

\section{Limitation}

The process to develop the GeriQ-EDఠ QIs started in 2014. In 2017 the QIs were published in German [22]. Although GeriQ-EDథ QIs refer to screening-tools based on current evidence (e.g. to screening for delirium or identification of geriatric needs) literature review for prior QIs had to be updated. In a recent systematic literature review (02/2020) no additional QIs were identified [search terms: 'emergency care' AND 'geriatrics'; database: PubMed; inclusion criteria: published between 2015 and 2020].

The majority of the 67 GeriQ-ED@ QIs are process- or structure indicators. The small number of outcome indicators was discussed with an expert for QI development. It was agreed that in the ED setting it is difficult to define outcome indicators due to the short stay of the patients and also the limited influence on the care received beyond the ED. Therefore, the development of outcome indicators in the field of emergency medicine is only possible with restrictions [12].

\section{Conclusions}

Demographic changes imply big challenges for the emergency care. QIs for this special setting offer a solution to 
improve geriatric emergency care and patient's safety. For the first time, GeriQ-ED $\odot$ provides a comprehensive set of 67 QIs which addresses the specialist care needs of older people in the ED to improve patient care.

The methodical approach used for the development of GeriQ-ED) corresponds to required methodical quality criteria. They are evidence-based, relevant and feasible. GeriQ-ED $\odot$ is based on a consensus among experts in the field. A prospective study is planned to evaluate the QIs in daily practice with a special focus on measuring criteria and feasibility.

However, in German Eds, GeriQ-EDఠ TOP 5 should be implemented as a minimum standard in geriatric emergency care.

\section{Supplementary information}

Supplementary information accompanies this paper at https://doi.org/10. 1186/s13049-020-00756-3.

Additional file 1.

\section{Authors' contributions}

The author(s) read and approved the final manuscript.

\section{Competing interests}

Susanne Schuster and Katrin Singler act as chair of geriatric emergency medicine section (ÄlPaNo) at the German Society of Emergency Medicine (DGINA). Katrin Singler act as chair of emergeny and intensiv medicine section at the German Society of Geriatrics (DGG). Harald Dormann act as chair of patient care and science section and advisory member of the board directors at the German Society of Emergency Medicine (DGINA).

\section{Author details \\ ${ }^{1}$ Faculty of Medicine, Friedrich-Alexander University Erlangen-Nürnberg, Erlangen, Germany. ${ }^{2}$ Emergency Department, Klinikum Fürth, Fürth, Germany. ${ }^{3}$ Institute for Nursing Research, Gerontology and Ethics, Lutheran University of Applied Sciences - Evangelische Hochschule Nürnberg, Nuremberg, Germany. ${ }^{4}$ Institute for Biomedicine of Ageing, Friedrich-Alexander Universität Erlangen-Nürnberg, Nuremberg, Germany. ${ }^{5}$ Geriatric Department - Medizinische Klinik 2, Geriatrie, Klinikum Nürnberg, Paracelsus Private Medical University, Nuremberg, Germany. ${ }^{6}$ Academic Geriatric Medicine, University of Southampton, University Hospital Southampton NHS FT, Southampton, UK. ${ }^{7}$ Charité - University of Medicine, Public Health Academy, Berlin, Germany. ${ }^{8}$ Charité - University of Medicine, Lernzentrum, Medical Skills Lab, Berlin, Germany. ${ }^{9}$ Competence Center Quality Management in Health Care, MDK Baden-Württemberg, Stuttgart, Germany.}

Received: 26 November 2019 Accepted: 22 June 2020

Published online: 16 July 2020

\section{References}

1. Samaras N, Chevalley T, Samaras D, Gold G. Older patients in the emergency department: a review. Ann Emerg Med. 2010;56(3):261-9.

2. Aminzadeh F, Dalziel WB. Older adults in the emergency department: a systematic review of patterns of use, adverse outcomes, and effectiveness of interventions. Ann Emerg Med. 2002;39(3):238-47.

3. Groening M, Grossmann F, Hilmer T, Schuster S, Singler K, Somasundaram R, Wilke P. ÄLPANO - erste Ergebnisse der DGINA-Umfrage zur Versorgung älterer Notfallpatienten. Notf Rettungsmedizin. 2015;18(Suppl 1):13.

4. Han JH, Wilber ST. Altered mental status in older emergency department patients. Clin Geriatr Med. 2013;29(1):101-36.

5. Griffiths D, Morphet J, Innes K, Crawford K, Williams A. Communication between residential aged care facilities and the emergency department. A review of the literature. Int J Nurs Stud. 2014;51 (11):1517-23.
6. Kessler C, Williams MC, Moustoukas JN, Pappas C. Transitions of care for the geriatric patient in the emergency department. Clin Geriatr Med. 2013;29(1):49-69.

7. Carpenter CR, Heard K, Wilber S, Ginde AA, Stiffler K, Gerson LW, et al. Research priorities for high-quality Geriatric emergency care: medication management, screening, and prevention and functional assessment. Acad Emerg Med. 2011;18(6):644-54.

8. Carpenter CR, Shah MN, Hustey FM, Heard K, Gerson LW, Miller DK. High yield research opportunities in geriatric emergency medicine: prehospital care, delirium, adverse drug events, and falls. J Gerontol A Biol Sci Med Sci. 2011;66(7):775-83.

9. Schnitker L, Martin-Khan M, Beattie E, Gray L. Negative health outcomes and adverse events in older people attending emergency departments: a systematic review. Australas Emerg Nurs J. 2011;14(3):141-62.

10. Salvi F, Morichi V, Grilli A, Giorgi R, De Tommaso G, Dessi-Fulgheri P. The elderly in the emergency department: a critical review of problems and solutions. Intern Emerg Med. 2007;2(4):292-301.

11. American GS, Geriatric E. D. G. T. F. American College of Emergency Physicians \& Emergency Nurses Association. Geriatric emergency department guidelines. Ann Emerg Med. 2014;63(5):e7.

12. Martin-Khan M, Burkett E, Schnitker L, Jones RN, Gray LC. Methodology for developing quality indicators for the care of older people in the emergency department. BMC Emerg Med. 2013;13(1):23.

13. Terrell KM, Hustey FM, Hwang U, Gerson LW, Wenger NS, Miller DK. Quality indicators for geriatric emergency care. Acad Emerg Med. 2009;16(5):441-9.

14. Conroy S, Nickel CH, Jónsdóttir AB, Fernandez M, Banerjee J, Mooijaart S, et al. The development of a European curriculum in Geriatric Emergency Medicine. Eur Geriatr Med. 2016;7(4):315-21.

15. Singler $K$, Dormann $H$, Dodt C, Heppner $H$, Püllen R, Burkhardt M, et al. Der geriatrische Patient in der Notaufnahme. Notf Rettungsmedizin. 2016;19(6):496-9.

16. Burkett E, Martin-Khan MG, Gray LC. Quality indicators in the care of older persons in the emergency department: a systematic review of the literature. Australas J Ageing. 2017;36(4):286-98

17. German Medical Science. Begriffe und Konzepte des Qualitätsmanagements - 3. Auflage. 2007. http://www.egms.de/static/en/journals/mibe/2007-3/ mibe000053.shtml.

18. Agency for Healthcare Research and Quality. Quality Indicator Measure Development, Implementation, Maintenance, and Retirement. 2011 http://www. qualityindicators.ahrq.gov/Downloads/Resources/Publications/2011/QI_Measure_ Development_Implementation_Maintenance_Retirement_Full_5-3-11.pdf.

19. Reiter A, Fischer B, Kötting J, Geraedts $M$, Jäckel WH, Döbler K. QUALIFY: ein Instrument zur Bewertung von Qualitätsindikatoren. Z Arztl Fortbild Qualitatssich. 2008;101(10):683-8.

20. Kuckartz AM, Kuckartz U. Qualitative text analysis with MAXQDA; 2002

21. Fitch K, Bernstein SJ, Aguilar MD, Burnand B, LaCalle JR, Lazaro P, et al. The RAND/ UCLA Appropriateness Method User's Manual. Santa Monica: RAND Corporation; 2001. https:/www.rand.org/pubs/monograph_reports/MR1269.html.

22. Schuster S, Singler K, Dormann H. GeriQ@ Quality Indicators for Geriatric Emergency Care - Entwicklung von Qualitätsindikatoren für die Versorgung von geriatrischen Notfallpatienten. 2017 https:/www.dgina.de/news/geriqc-quality-indicators-for-geriatric-emergency-care-entwicklung-vonqualitatsindikatoren-fur-die-versorgung-von-geriatrischennotfallpatienten_63. Accessed 29 June 2020

23. LaMantia MA, Messina FC, Hobgood CD, Miller DK. Screening for delirium in the emergency department: a systematic review. Ann Emerg Med. 2014; 63(5):551-60.

24. Han JH, Wilson A, Ely EW. Delirium in the older emergency department patient: a quiet epidemic. Emerg Med Clin North Am. 2010;28(3):611-31.

25. Schnitker LM, Martin-Khan M, Burkett E, Brand CA, Beattie ER, Jones RN, Gray LC. Structural quality indicators to support quality of care for older people with cognitive impairment in emergency departments. Acad Emerg Med. 2015:22:273-84

26. Pisani MA, Kong SYJ, Kasl SV, Murphy TE, Araujo K, Van Ness PH. Days of delirium are associated with 1-year mortality in an older intensive care unit population. Am J Respir Crit Care Med. 2009;180(11):1092-7.

27. Grossmann FF, Hasemann W, Graber A, Bingisser R, Kressig RW, Nickel CH. Screening, detection and management of delirium in the emergency department-a pilot study on the feasibility of a new algorithm for use in older emergency department patients: the modified confusion assessment method for the emergency department (mCAM-ED). Scand J Trauma Resusc Emerg Med. 2014;22(1):19. 
28. Hasemann W, Grossmann FF, Stadler R, Bingisser R, Breil D, Hafner M, et al Screening and detection of delirium in older ED patients: performance of the modified Confusion Assessment Method for the Emergency Department (mCAM-ED). A two-step tool. Intern Emerg Med. 2018;13(6):15-22.

29. O'Sullivan D, Brady N, Manning E, O'Shea E, O'Grady S, O 'Regan N, Timmons S. Validation of the 6 -Item Cognitive Impairment Test and the 4AT test for combined delirium and dementia screening in older Emergency Department attendees. Age Ageing. 2017;1:1-7.

30. Hustey FM, Wallis N, Miller J. Inappropriate prescribing in an older ED population. Am J Emerg Med. 2007;25:804-7.

31. Hohl CM, Dankoff J, Colacone A, Afilalo M. Polypharmacy, adverse drugrelated events, and potential adverse drug interactions in elderly patients presenting to an emergency department. Ann Emerg Med. 2001;38:666-71.

32. Dormann H, Sonst A, Müller F, Vogler R, Patapovas A, Pfistermeister B, et al. Adverse drug events in older patients admitted as an emergency: the role of potentially inappropriate medication in elderly people (PRISCUS). Dtsch Arztebl Int. 2013;110(13):213.

33. Schurig AM, Böhme M, Just KS, Scholl C, Dormann H, Plank-Kiegele B, et al. Adverse Drug Reactions (ADR) and Emergencies: The Prevalence of Suspected ADR in Four Emergency Departments in Germany. Dtsch Arztebl Int. 2018;115(15):251.

34. Budnitz DS, Shehab N, Kegler SR, Richards CL. Medication use leading to emergency department visits for adverse drug events in older adults. Ann Intern Med. 2007;147:755-65.

35. Howard RL, Avery AJ, Slavenburg S, Roya S, Pipe G, Lucassen P, Pirmohamed M. Which drugs cause preventable admissions to hospital? A systematic review. Br J Clin Pharmacol. 2007;63:136-47.

36. Laroche ML, Charmes JP, Nouaille Y, Picard N, Merle L. Is inappropriate medication use a major cause of adverse drug reactions in the elderly? $\mathrm{Br} J$ Clin Pharmacol. 2007:63:177-86.

37. Gurwitz JH, Field TS, Harrold LR, Rothschild J, Debellis K, Seger AC, et al, Incidence and preventability of adverse drug events among older persons in the ambulatory setting. JAMA. 2003;289:1107-16.

38. Lavan AH, Gallagher P. Predicting risk of adverse drug reactions in older adults. Ther Adv Drug Saf. 2016;7(1):11-22.

39. Hogan TM, Losman ED, Carpenter CR, Sauvigne K, Irmiter C, Emanuel L, Leipzig RM. Development of geriatric competencies for emergency medicine residents using an expert consensus process. Acad Emerg Med. 2010;17:316-24.

40. Carpenter CR, Shelton E, Fowler S, Suffoletto B, Platts-Mills TF, Rothman RE, Hogan TM. Risk factors and screening instruments to predict adverse outcomes for undifferentiated older emergency department patients: a systematic review and meta-analysis. Acad Emerg Med. 2015;22(1):1-21.

41. Hwang U, Carpenter C. Assessing geriatric vulnerability for post emergency department adverse outcomes: challenges abound while progress is slow. Emerg Med J. 2015;33(1):2-3.

42. Ellis G, Whitehead MA, Robinson D, O'Neill D, Langhorne P. Comprehensive geriatric assessment for older adults admitted to hospital: meta-analysis of randomised controlled trials. BMJ. 2011;343:d6553.

43. Carpenter CR, Avidan MS, Wildes T, Stark S, Fowler SA, Lo AX. Predicting geriatric falls following an episode of emergency department care: a systematic review. Acad Emerg Med. 2014;21(10):1069-82.

44. Rutschmann OT, Chevalley T, Zumwald C, Luthy CS, Vermeulen B, Sarasin F. Pitfalls in the emergency department triage of frail elderly patients without specific complaints. Swiss Med Wkly. 2005;135(9-10):145-50.

45. Büscher A, Blumenberg P. Expertenstandard Sturzprophylaxe in der Pflege: DNQP; 2013

46. Higashi T, Shekelle PG, Adams JL, Kamberg CJ, Roth CP, Solomon DH, et al. Quality of care is associated with survival in vulnerable older patients. Ann Intern Med. 2005;143:274-81.

47. Schnitker LM, Martin-Khan M, Burkett E, Beattie ER, Jones RN, Gray LC. Process quality indicators targeting cognitive impairment to support quality of care for older people with cognitive impairment in emergency departments. Acad Emerg Med. 2015;22:285-98.

\section{Publisher's Note}

Springer Nature remains neutral with regard to jurisdictional claims in published maps and institutional affiliations.

Ready to submit your research? Choose BMC and benefit from:

- fast, convenient online submission

- thorough peer review by experienced researchers in your field

- rapid publication on acceptance

- support for research data, including large and complex data types

- gold Open Access which fosters wider collaboration and increased citations

- maximum visibility for your research: over $100 \mathrm{M}$ website views per year

At BMC, research is always in progress.

Learn more biomedcentral.com/submissions 